\title{
Distinct Contributions of Dopamine in the Dorsolateral Striatum and Nucleus Accumbens Shell to the Reinforcing Properties of Cocaine
}

\author{
Maartje MJ Veeneman', Mark H Broekhoven', Ruth Damsteegt' and Louk JMJ Vanderschuren*, , 2 \\ 'Department of Neuroscience and Pharmacology, Rudolf Magnus Institute of Neuroscience, University Medical Center Utrecht, Utrecht, \\ The Netherlands; ${ }^{2}$ Division of Behavioural Neuroscience, Department of Animals in Science and Society, Faculty of Veterinary Medicine, \\ Utrecht University, Utrecht, The Netherlands
}

\begin{abstract}
Dopaminergic neurotransmission in the dorsal and ventral striatum is thought to be involved in distinct aspects of cocaine addiction. Ventral striatal dopamine mediates the acute reinforcing properties of cocaine, whereas dopamine in the dorsolateral striatum (DLS) is thought to become involved in later stages of the addiction process to mediate well-established cue-controlled drug seeking. However, it is unclear whether the DLS also has a role in the reinforcing properties of cocaine itself. Therefore, we systematically investigated the involvement of dopamine in dorsal and ventral striatal regions in cocaine self-administration, using various schedules of reinforcement in animals with limited drug taking experience. Intra-DLS infusion of the dopamine receptor antagonist $\alpha$-flupenthixol did not affect the acquisition of cocaine self-administration, increased cocaine self-administration under a fixed ratio-I (FR-I) schedule of reinforcement, caused a rightward and downward shift of the dose-response curve of cocaine under an FR-I schedule of reinforcement and decreased responding for cocaine under a progressive ratio (PR) schedule of reinforcement. Infusion of $\alpha$-flupenthixol into the ventral nucleus accumbens (NAcc) shell inhibited the acquisition of cocaine self-administration, reduced responding for the drug under FR-I and PR schedules of reinforcement, and caused a downward shift of the dose-response curve of cocaine self-administration under an FR-I schedule of reinforcement. These data show that dopamine in both the DLS and NAcc shell is involved in cocaine reinforcement. We suggest that the DLS and the NAcc shell mediate somewhat distinct facets of the reinforcing properties of cocaine, related to its rewarding and motivational aspects, respectively.

Neuropsychopharmacology (20 I2) 37, 487-498; doi:I0.1038/npp.20 I I.209; published online I4 September 201 I
\end{abstract}

Keywords: cocaine; self-administration; reinforcement; dopamine; nucleus accumbens shell; dorsolateral striatum

\section{INTRODUCTION}

Cocaine addiction is a devastating neuropsychiatric disorder characterized by a loss of control over drug intake. The descent from casual, recreational cocaine use into the compulsive patterns of cocaine taking that characterize addiction, is thought to result from a multitude of druginduced functional changes in the neural circuits involved in positive and negative emotions, incentive motivation, habit formation and cognitive control over behavior (Robinson and Berridge, 2003; Koob et al, 2004; Volkow and Li, 2004; Bechara, 2005; Everitt and Robbins, 2005; Vanderschuren and Everitt, 2005; Perry and Carroll, 2008; Pierce and Vanderschuren, 2010). It is thought that one of the critical

*Correspondence: LJMJ Vanderschuren, Department of Neuroscience and Pharmacology, Rudolf Magnus Institute of Neuroscience, University Medical Center Utrecht, Universiteitsweg 100, 3584 CG Utrecht, The Netherlands. Tel: + 3188756 88।I, Fax: + 31887568 155, E-mail: I.j.m.j.vanderschuren@umcutrecht.nl

Received 2 May 2011; revised 5 August 2011; accepted 10 August 2011 neural changes that mediates the transition from casual to compulsive cocaine use is a change in the striatal regions in control of drug seeking and taking, that is, a progressive involvement of dorsal striatal regions in cocaine use (Everitt and Robbins, 2005; Pierce and Vanderschuren, 2010).

The dopaminergic innervation of the ventral striatum has been widely implicated in the reinforcing properties of cocaine (Wise, 2004; Pierce and Kumaresan, 2006). Drugnaive rats self-administer cocaine into the most ventromedial regions of the striatum, that is, the nucleus accumbens (NAcc) shell and the olfactory tubercle (Rodd-Henricks et al, 2002; Ikemoto, 2003), and the reinforcing properties of cocaine are reduced after infusion of dopamine receptor antagonists into the NAcc (Maldonado et al, 1993; McGregor and Roberts, 1993; Caine et al, 1995; Bachtell et al, 2005; Bari and Pierce, 2005; Suto et al, 2009), or dopamine depletion of the NAcc (Roberts et al, 1977, 1980; Pettit et al, 1984; Gerrits and van Ree, 1996).

The dorsolateral striatum (DLS) is known to mediate stimulus-response habit learning (Packard and Knowlton, 2002; Yin and Knowlton, 2006). This region is thought to 
become involved in drug seeking after lengthy drug taking experience, when drug use becomes habitual and stimulus driven (Everitt and Robbins, 2005; Pierce and Vanderschuren, 2010). Evidence to support this gradual involvement of dorsal striatal regions in cocaine use comes from selfadministration studies in primates. These experiments have shown that with increasing cocaine self-administration experience, changes in the density of the dopamine D2 receptor and the dopamine transporter spread from ventral to dorsal striatal regions (Moore et al, 1998; Letchworth et al, 2001; Nader et al, 2002; Porrino et al, 2004). Behavioral studies have associated dopamine in the DLS with well-established, perhaps habitual, cue-controlled cocaine seeking in rats. During cue-controlled cocaine seeking under a second-order schedule of reinforcement, dopamine overflow increased in the DLS, but not in the ventral striatum, and infusion of a dopamine receptor antagonist into the DLS reduced cue-controlled cocaine seeking (Ito et al, 2000, 2002; Vanderschuren et al, 2005; Belin and Everitt, 2008). Further support for a role of the DLS in habitual cocaine seeking comes from a recent study that showed that functional inactivation of the DLS restored the sensitivity of cocaine seeking to devaluation of the drug outcome, that is, extinction of the cocaine taking response (Zapata et al, 2010). Moreover, exposure to drug cues in cocaine addicts increases dopamine activity in the dorsal striatum, and this increase in dopamine activity is correlated with the intensity of cue-induced craving (Volkow et al, 2006; Wong et al, 2006). However, while the DLS gains an important role in cocaine seeking after prolonged drug self-administration, ventral striatal regions remain involved. For example, AMPA glutamate receptors in the NAcc core mediate well-established cue-controlled drug seeking (Di Ciano and Everitt, 2001), and the development of compulsive, addiction-like cocaine selfadministration has been shown to be associated with impaired long-term depression in NAcc core neurons (Kasanetz et al, 2010).

Based on the studies discussed above, it has been hypothesized that ventral striatal mechanisms have an important role in primary drug reinforcement, while the dorsal striatum becomes involved in cue-controlled forms of addictive behavior after extensive drug taking experience (Everitt and Robbins, 2005; Pierce and Vanderschuren, 2010). However, as its role in primary drug reinforcement is largely unexplored (Maldonado et al, 1993; Caine et al, 1995; Vanderschuren et al, 2005; Suto et al, 2011), it is not clear whether the dorsal striatum is only involved in habitual cuecontrolled drug seeking in highly drug-experienced subjects. Therefore, we examined the involvement of dopamine neurotransmission in different regions of the ventral and dorsal striatum in cocaine self-administration in rats with limited drug taking experience.

\section{MATERIALS AND METHODS}

\section{Subjects}

Male Wistar rats (Charles River) weighing $250 \pm 15 \mathrm{~g}$ at arrival were singly housed in Macrolon cages $(40 \times 26 \times$ $20 \mathrm{~cm}$ ) in climate-controlled rooms (temperature: $21 \pm 2{ }^{\circ} \mathrm{C}$, $60-65 \%$ relative humidity) under a reversed $12 \mathrm{~h}$ day/night cycle (lights on $1900 \mathrm{~h}$ ). Animals were allowed to habituate to the housing conditions for at least 9 days before surgery. Rats received $20 \mathrm{~g}$ chow (SDS) per day, which is sufficient to maintain bodyweight and growth. Water was available ad libitum. Self-administration sessions were carried out between 0900 and $1800 \mathrm{~h}$ for 5-7 days a week. Experiments were approved by the Animal Ethics Committee of Utrecht University, and were conducted in agreement with Dutch (Wet op de dierproeven, 1996) and European regulations (Guideline 86/609/EEC).

\section{Surgery}

Rats were anaesthetized with ketamine- $\mathrm{HCl}(75 \mathrm{mg} / \mathrm{kg}$ i.m.) and medetomidine $(0.4 \mathrm{mg} / \mathrm{kg}$ s.c.) and a catheter (CamCaths) was placed into the right jugular vein. Next, the rats were positioned in a stereotaxic apparatus and $26 \mathrm{G}$ guide cannulas (Plastics One) were implanted bilaterally, $1 \mathrm{~mm}$ above target structures. Coordinates relative to bregma (Paxinos and Watson, 1998) were as follows: NAcc shell: anteroposterior (AP) $+1.2 \mathrm{~mm}$, mediolateral (ML) $\pm 2.8 \mathrm{~mm}$, dorsoventral (DV) $-7.5 \mathrm{~mm}$ at an angle of $10^{\circ}$; NAcc core: $+1.2 \mathrm{~mm} \mathrm{AP}, \pm 2.8 \mathrm{~mm} \mathrm{ML},-6.4 \mathrm{~mm} \mathrm{DV}$ at an angle of $10^{\circ}$; dorsomedial striatum (DMS): $+1.2 \mathrm{~mm} \mathrm{AP}$, $\pm 3.6 \mathrm{~mm} \mathrm{ML},-4.1 \mathrm{~mm} \mathrm{DV}$ at an angle of $22^{\circ}$; DLS: $+1.2 \mathrm{~mm} \mathrm{AP}, \pm 4.2 \mathrm{~mm} \mathrm{ML},-3.7 \mathrm{~mm} \mathrm{DV}$ at an angle of $10^{\circ}$. Cannulas were fixed using stainless steel screws and dental acrylic and a stylet was inserted into each cannula. Carprofen $(5 \mathrm{mg} / \mathrm{kg})$ was administrated once before and twice after surgery. Gentamycin $(5 \mathrm{mg} / \mathrm{kg})$ was administered before surgery and for 5 days post-surgery. Animals were allowed at least 9 days to recover from surgery.

\section{Apparatus}

Operant conditioning chambers $(29.5 \times 24 \times 25 \mathrm{~cm}$; $1 \times \mathrm{w} \times \mathrm{h}$; Med Associates) situated in light- and sound-attenuating cubicles equipped with a ventilation fan were used. Each chamber contained two retractable levers. A cue light was present above each lever and a house light was located on the opposite wall. Sucrose pellets $(45 \mathrm{mg}$, formula F, Research Diets) could be delivered at the wall opposite to the levers via a dispenser. Priming infusions of cocaine were never given. After each session, catheters were flushed with $0.15 \mathrm{ml}$ heparinized saline. Experimental events and data recording were controlled using MED-PC for Windows.

\section{Microinfusions}

Microinfusions were made through $33 \mathrm{G}$ injector cannulas (Plastics One) that extended $1.0 \mathrm{~mm}$ below the guide cannulas. Using a syringe pump (Harvard Apparatus), bilateral infusions $(0.3 \mu \mathrm{l} / \mathrm{side} / 60 \mathrm{~s})$ were made, and the injectors were left in place for another $60 \mathrm{~s}$ to allow for diffusion. Self-administration sessions began $7 \mathrm{~min}$ after the start of the microinfusion.

\section{Self-Administration}

Fixed ratio-1 schedule of reinforcement. Rats were trained to self-administer cocaine under a fixed ratio-1 (FR-1) schedule of reinforcement. During $2 \mathrm{~h}$ sessions, two levers 
were present, one of which was designated as active. The position of the active and inactive levers was counterbalanced between animals. Pressing the active lever resulted in the infusion of $0.25 \mathrm{mg}$ cocaine in $0.1 \mathrm{ml}$ saline over $5.6 \mathrm{~s}$, retraction of the levers, switching off of the house light, followed by a 20 -s time-out period. During the infusion, the cue light above the lever was illuminated. When rats showed stable cocaine intake, defined as $<10 \%$ variation over three sessions, they received a habituation infusion with saline into the NAcc shell, NAcc core, DMS or DLS. After at least 2 more days of stable responding, rats received infusions of $\alpha$-flupenthixol $(0,3.75,7.5$ and $15.0 \mu \mathrm{g} / \mathrm{side})$. Each animal received all doses of $\alpha$-flupenthixol in a counterbalanced manner. Test sessions were separated by at least one session without treatment. In separate experiments, rats were trained to self-administer sucrose under an FR-1 schedule during $30 \mathrm{~min}$ sessions. Pressing the active lever produced one sucrose pellet, followed by a 5.6-s time-out. Animals were fed ad libitum once they acquired sucrose selfadministration to avoid that hunger influenced the results. After responding had stabilized, rats received a habituation infusion, followed by counterbalanced infusions with 0 and $15.0 \mu \mathrm{g} \alpha$-flupenthixol/side into the NAcc shell or the DLS.

FR-1 dose-response curve for cocaine. Rats were trained to self-administer cocaine under an FR-1 schedule of reinforcement as above. After stabilization of cocaine intake, rats received a habituation infusion into the NAcc shell or DLS. After at least 2 more days of stable responding, rats received counterbalanced infusions with 0 and $15.0 \mu \mathrm{g} \alpha$-flupenthix$\mathrm{ol} /$ side before testing for a within-session dose-response curve for cocaine. Dose-response sessions were separated by at least two FR-1 sessions without treatment. To circumvent effects of the initial loading phase of cocaine on the results, dose-response curve sessions started with $30 \mathrm{~min}$ of self-administration of $0.25 \mathrm{mg} /$ infusion cocaine. Subsequently, the animals were allowed to respond for descending doses of cocaine $(0.5,0.25,0.125,0.063$ and $0.031 \mathrm{mg} /$ infusion). Each dose was available for $1 \mathrm{~h}$ and the introduction of a new dose was preceded by a 10-min timeout period.

Progressive ratio schedule of reinforcement. A seekingtaking (ST) chain schedule of reinforcement (Olmstead et al, 2000) was used, with a progressive ratio (PR) requirement on the seeking link and an FR-1 requirement on the taking link. The assignment of the left and right lever as the seeking and taking levers was counterbalanced between animals. Training started with acquisition of cocaine taking under an FR-1 schedule of reinforcement, as above, except that only one lever was present. Next, the ST-PR schedule of reinforcement was introduced. The STPR sessions started with the illumination of the house light and insertion of the seeking lever. Under this schedule, animals had to meet a response requirement on the seeking lever that progressively increased after every earned reward $(1,2,4,6,9,12,15,20,25$, etc; Richardson and Roberts, 1996), to get access to the taking lever. When rats met the response requirement on the seeking lever, the lever retracted and the taking lever was inserted. One press on this taking lever led to a cocaine infusion $(0.25 \mathrm{mg} /$ infusion), retraction of the lever, the switching off of the house light, illumination of the cue light above the taking lever for the duration of the infusion, followed by a 10-min time-out period during which both levers remained retracted. After the time-out period, the cycle re-started with the insertion of the seeking lever and illumination of the house light. Sessions continued until rats failed to obtain a reward within $1 \mathrm{~h}$. The highest number of seeking responses an animal performed for one single reward was defined as the breakpoint. When rats showed stable cocaine intake, defined as $<2$ rewards variation over the last three sessions, they received a habituation infusion into the NAcc shell or DLS. After at least 2 more days of stable responding, rats received bilateral infusions of $\alpha$-flupenthixol $(0,3.75$, 7.5 and $15.0 \mu \mathrm{g} / \mathrm{side})$. Each animal received all doses of $\alpha$-flupenthixol in a counterbalanced manner. Test sessions were separated by at least one session without treatment.

Acquisition of cocaine self-administration. Rats received a habituation infusion with saline into the NAcc shell or DLS. Starting the next day, rats were allowed to self-administer cocaine for 10 consecutive sessions under an FR-1 schedule of reinforcement as above. Preceding the first five sessions, rats received 0 or $15 \mu \mathrm{g} \alpha$-flupenthixol/side into the NAcc shell or DLS, followed by five sessions without treatment.

\section{Histology}

Rats were killed using an overdose of pentobarbital. The brains were removed, immediately fresh frozen on dry ice and stored at $-80^{\circ} \mathrm{C}$. Coronal sections $(20 \mu \mathrm{m})$ were sliced on a cryostat and every fifth section was stained with haemaluin and eosin. Cannula placements were assessed under a light microscope.

\section{Solutions}

Cocaine-HCl (Bufa BV) and cis-(Z)- $\alpha$-flupenthixol-diHCl (Sigma) were dissolved in sterile physiological saline $(0.9 \%$ $\mathrm{NaCl})$.

\section{Statistics}

Cocaine self-administration under an FR-1 schedule of reinforcement was analyzed using a repeated measures ANOVA and post hoc comparisons were made using paired $t$-tests. Response patterns during a session were analyzed using a two-way repeated measures ANOVA with time as within-subjects factor and $\alpha$-flupenthixol dose as betweensubjects factor. Sucrose self-administration under an FR-1 schedule of reinforcement was analyzed using paired $t$-tests. The cocaine dose-response self-administration experiments were analyzed using a two-way repeated measures ANOVA with cocaine dose as within-subjects factor and $\alpha$ flupenthixol as between-subjects factor. Post hoc comparisons were made using paired $t$-tests. Breakpoints in the ST-PR experiments are derived from an escalating curve, which violates the homogeneity of variance. Therefore, we analyzed breakpoints using the non-parametric Friedman test, followed by a post hoc Wilcoxon signed ranks test. Acquisition of cocaine self-administration was analyzed using a repeated measures ANOVA with session as withinsubjects factor and $\alpha$-flupenthixol as between-subjects 
factor. For the acquisition of cocaine self-administration experiments, two separate analyses were performed: sessions 1-5 (acquisition of self-administration during treatment) and sessions 6-10 (self-administration without treatment). Next, we performed a planned comparison within and between session 5 and 6 (ie, the last session with treatment and the first session without treatment) using paired and unpaired $t$-tests, respectively.

\section{RESULTS}

\section{Dopamine in Striatal Regions and Cocaine Self-} Administration: FR-1 Schedule of Reinforcement

We first assessed in which striatal areas dopamine has a role in cocaine self-administration after limited cocaine use under an FR-1 schedule of reinforcement. We bilaterally infused different concentrations of the dopamine receptor antagonist $\alpha$-flupenthixol into the NAcc shell, NAcc core, DMS and the DLS (Figure 1) once animals had acquired cocaine self-administration under an FR-1 schedule of reinforcement. The unit dose of cocaine used $(0.25 \mathrm{mg} /$ infusion) is on the descending limb of the dose-response curve of cocaine self-administration (see Figure 3). Acquisition of stable levels of responding under this schedule took $11.5 \pm 0.5$ sessions. Infusion of $\alpha$-flupenthixol into the NAcc shell decreased cocaine self-administration $\left(\mathrm{F}_{3,27}=3.71\right.$, $p=0.02)$. Post hoc analysis showed that responding for cocaine was significantly reduced after intra-NAcc shell infusion of $15 \mu \mathrm{g} \alpha$-flupenthixol (Figure 2a). Analysis of the response patterns showed that, after an initial loading phase' of $\sim 20 \mathrm{~min}$, animals displayed stable levels of cocaine intake during the remainder of the 2-h selfadministration session. $\alpha$-Flupenthixol reduced cocaine intake throughout the session (time, $F_{5,180}=94.11$, $p<0.001$; treatment, $\mathrm{F}_{3,36}=3.06, p=0.04$; time $\times$ treatment, $\mathrm{F}_{15,180}=0.82, p=0.66$; Figure 2e). Infusion of $\alpha$-flupenthixol into the NAcc core and DMS did not affect cocaine selfadministration (NAcc core, $\mathrm{F}_{3,15}=0.42, p=0.75$; DMS, $\mathrm{F}_{3,24}=2.44, p=0.09$; Figure $2 \mathrm{~b}$ and $\mathrm{c}$ ). Infusion of $\alpha$ flupenthixol into the DLS resulted in a dose-dependent increase in cocaine self-administration $\left(\mathrm{F}_{3,27}=12.70\right.$, $p<0.001)$. Post hoc analysis showed that responding for cocaine was significantly enhanced after intra-DLS infusion of 7.5 and $15 \mu \mathrm{g} \alpha$-flupenthixol (Figure 2d). Analysis of the response patterns showed that $\alpha$-flupenthixol increased cocaine intake throughout the session (time, $\mathrm{F}_{5,180}=28.22$, $p<0.001$; treatment, $\mathrm{F}_{3,36}=7.99, p<0.001$; time $\times$ treatment $F_{15,180}=0.21, p=0.99$; Figure $2 \mathrm{f}$ ). The absence of an interaction between time and treatment for the effects of $\alpha$-flupenthixol in the NAcc shell and DLS shows that the effects of the dopamine receptor antagonist did not change as the session progressed. This indicates that the effects of $\alpha$-flupenthixol on cocaine self-administration were exerted

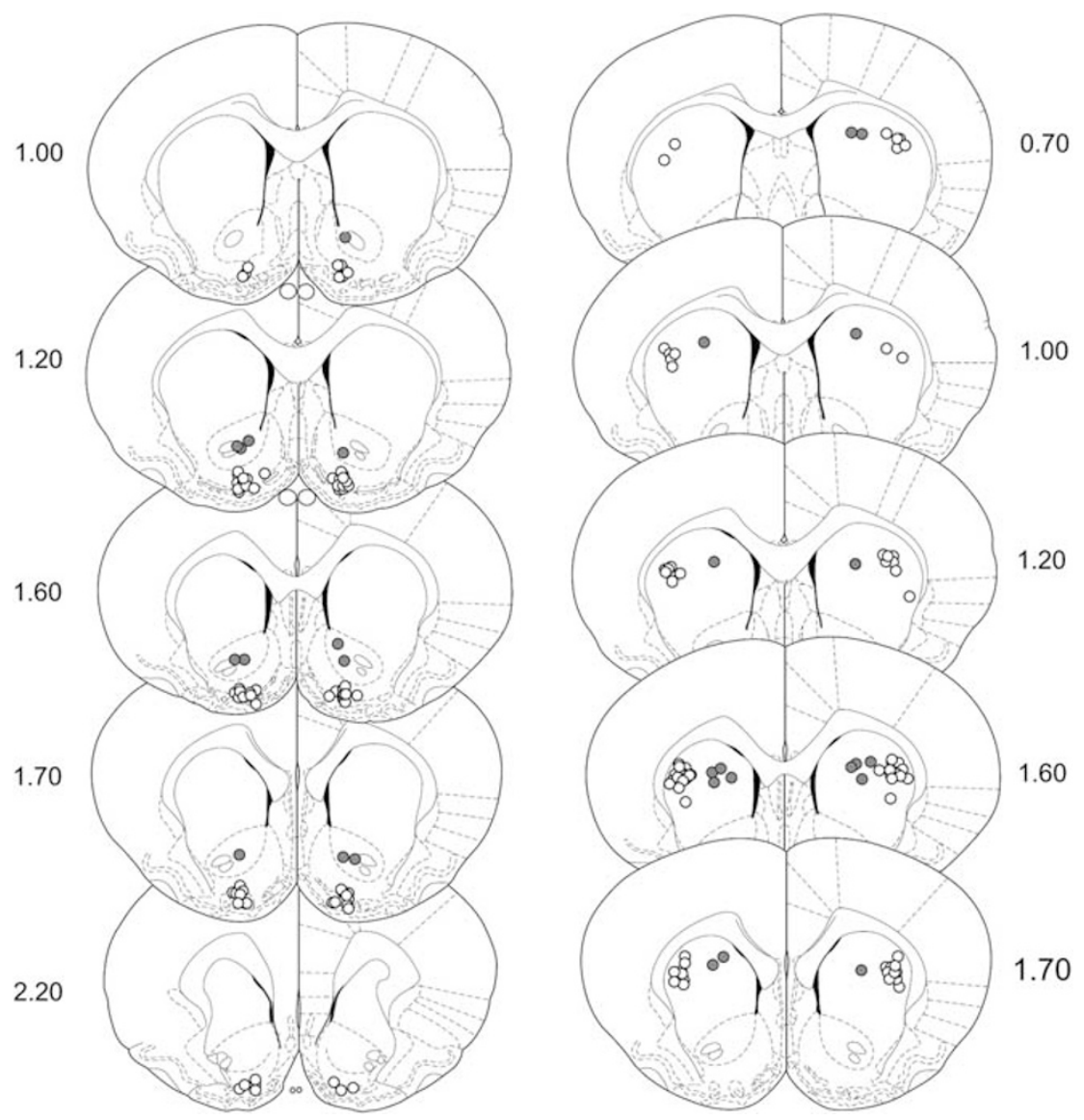

Figure I Schematic representation of the bilateral flupenthixol injection sites in coronal sections. On the left the NAcc shell (open circles) and the NAcc core (gray circles) infusion sites, and on the right the DLS (open circles) and the DMS (gray circles) infusion sites. Numbers indicate the distances anterior to bregma in millimeters (adapted from Paxinos and Watson, 1998). 

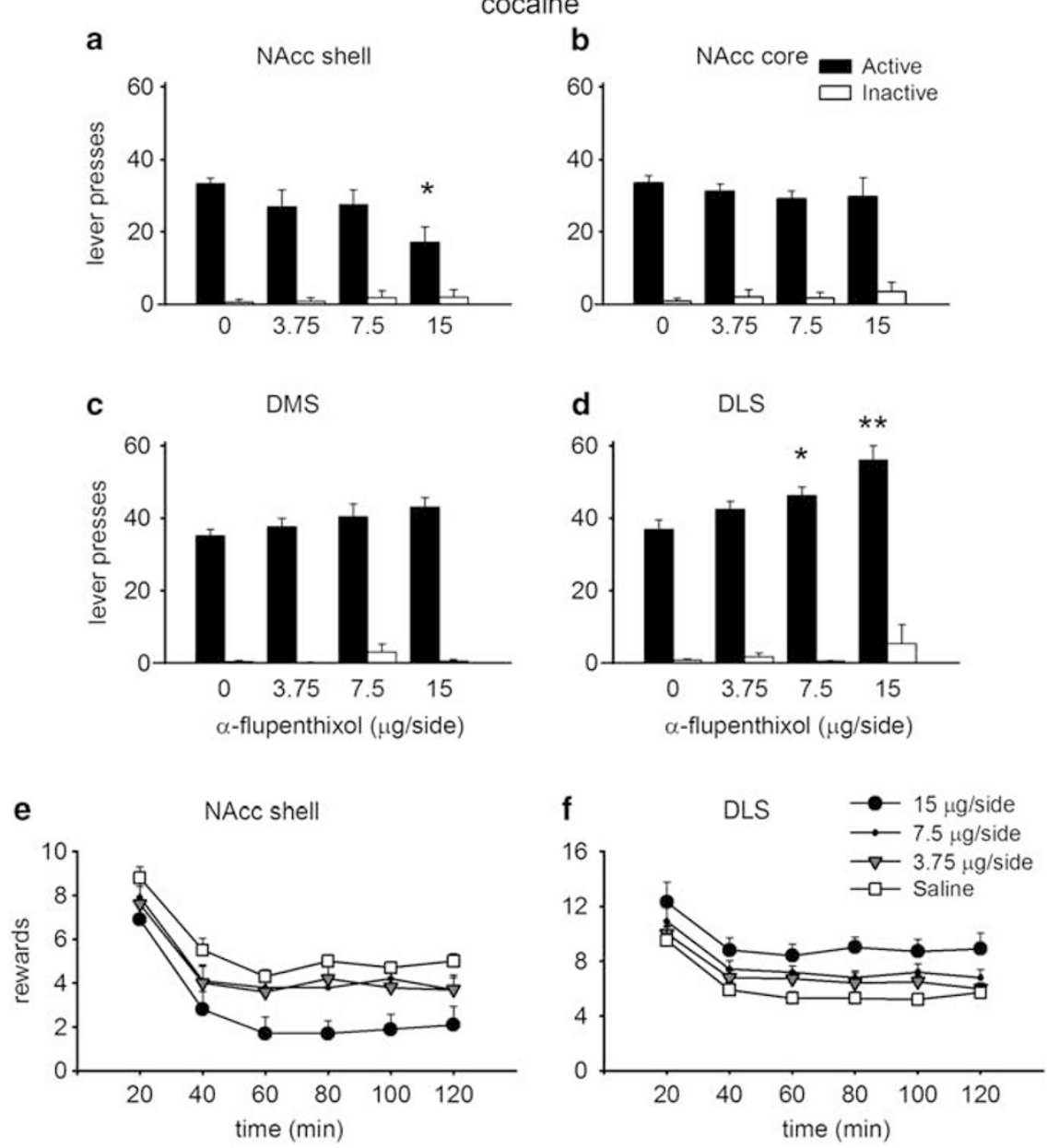

sucrose
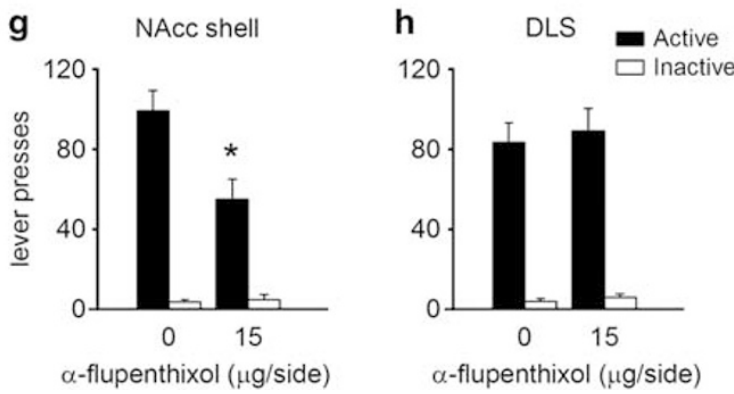

Figure 2 Effects of the intracerebral infusions of $\alpha$-flupenthixol on intravenous cocaine self-administration under an FR-I schedule of reinforcement. Graphs express the total number of active (black bars) and inactive (white bars) lever presses during the 2-h self-administration session following infusion of saline or $\alpha$-flupenthixol into (a) the NAcc shell $(n=10)$, (b) the NAcc core $(n=6)$, (c) the DMS $(n=9)$ or $(d)$ the DLS $(n=10)$. Number of rewards (ie, cocaine infusions) per 20 min of the 2-h self-administration session following infusion of saline or $\alpha$-flupenthixol into either (e) the NAcc shell or ( $f$ ) the DLS. Effects of intracerebral infusions of $\alpha$-flupenthixol on sucrose self-administration under an FR-I schedule. Graphs express the total number of active (black bars) and inactive (white bars) lever presses during the 30-min self-administration session following infusion of saline or $\alpha$-flupenthixol into either (g) the NAcc shell $(n=8)$ or $(h)$ the DLS $(n=7)$. Data are presented as mean \pm SEM, $* p<0.05$, different from saline (paired $t$-test).

in the NAcc shell and DLS, respectively, rather than being the result of diffusion of the dopamine receptor antagonist into adjacent areas. Inactive lever presses were not affected by $\alpha$-flupenthixol in any of the regions (NAcc shell, $\mathrm{F}_{3,27}=2.50, p=0.08 ;$ NAcc core, $\mathrm{F}_{3,15}=2.23, p=0.13$; DMS, $\mathrm{F}_{3,24}=1.32, \quad p=0.29 ; \quad \mathrm{DLS}, \mathrm{F}_{3,27}=0.70, \quad p=0.56$; Figure $2 \mathrm{a}-\mathrm{d}) . \alpha$-Flupenthixol infusion into the NAcc shell decreased responding for sucrose under an FR-1 schedule of reinforcement (rewards, $t_{7}=4.74, p=0.002$; inactive lever presses, $t_{7}=-0.42, p=0.68$; Figure $2 \mathrm{~g}$ ), but infusion of $\alpha$-flupenthixol into the DLS did not affect sucrose selfadministration (rewards, $t_{6}=-1.93, p=0.10$; inactive lever presses, $t_{6}=-1.80, p=0.12$; Figure $2 \mathrm{~h}$ ). These experiments indicate an important role for dopamine in the NAcc shell and the DLS in responding for cocaine under an FR-1 schedule of reinforcement. 

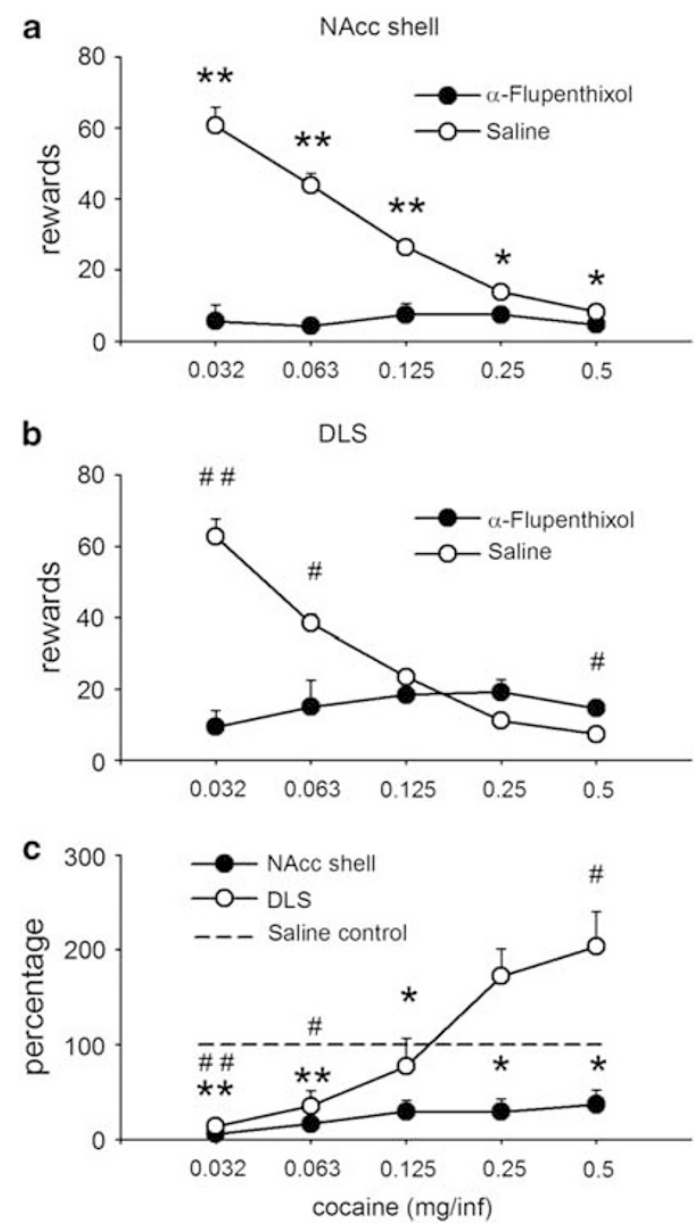

Figure 3 Dose-response curve functions of cocaine self-administration. Graphs express ( $a, b)$ the number of rewards (ie, cocaine infusions) obtained after infusion of saline or I $5 \mu \mathrm{g} \alpha$-flupenthixol into (a) the NAcc shell $(n=5)$ or $(b)$ the DLS $(n=5)$ during intravenous cocaine selfadministration in a within-session dose-response curve under an FR-I schedule of reinforcement, where each dose of cocaine was available for I h. (c) The relative effect of $\alpha$-flupenthixol into the NAcc shell and DLS on intravenous cocaine self-administration, as a percentage of responding after saline infusion (ie, responding under saline was set at 100\%). Data are presented as mean $\pm \mathrm{SEM},{ }^{*} p<0.05,{ }^{*} * 00.01$; ${ }^{\#} p<0.05$, \# $p<0.01$, different from saline for NAcc shell and DLS, respectively (paired $t$-test),

\section{Dopamine in NAcc Shell and DLS and Cocaine Self-Administration: Dose-Response Curve Under an FR-1 Schedule of Reinforcement}

We next examined whether the effects of $\alpha$-flupenthixol infusions into the NAcc shell and the DLS on cocaine selfadministration under the FR-1 schedule of reinforcement were the result of a change in the sensitivity to the reinforcing properties of the drug. To that aim, we assessed the effects of $\alpha$-flupenthixol infusions into the NAcc shell and DLS on a within-session dose-response curve of cocaine self-administration under an FR-1 schedule of reinforcement. In animals responding for descending unit doses of cocaine under an FR-1 schedule of reinforcement, infusion of $\alpha$-flupenthixol into the NAcc shell suppressed responding for cocaine for all unit doses of cocaine (treatment, $\quad \mathrm{F}_{1,8}=59.66, \quad p<0.001$; treatment $\times$ dose, $\mathrm{F}_{4,32}=58.46, p<0.001$; Figure $3 \mathrm{a}$ and $\mathrm{c}$ ), resulting in a
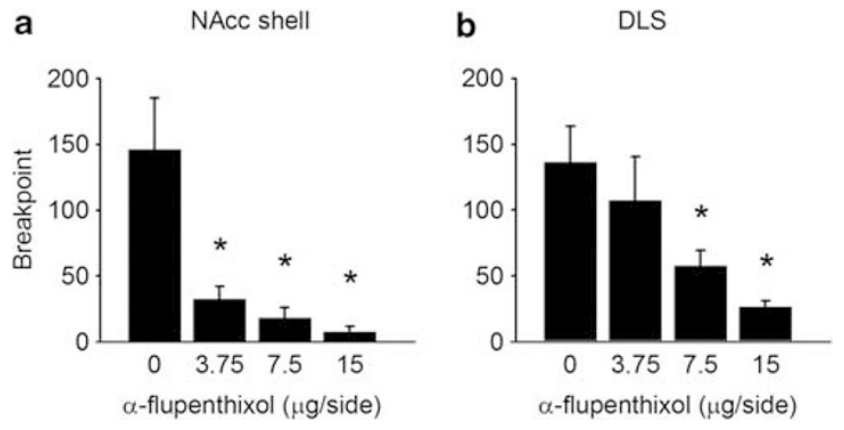

Figure 4 Breakpoints under the ST(PR) schedule of cocaine selfadministration after infusions of saline or $\alpha$-flupenthixol in either (a) the NAcc shell $(n=8)$ or (b) the DLS $(n=7)$. Data are presented as mean \pm SEM, $* p<0.05$, different from saline (Wilcoxon signed ranks test).

downward shift of the dose-response curve. Infusion of $\alpha$-flupenthixol into the DLS increased cocaine self-administration for doses $>0.125 \mathrm{mg} /$ infusion. However, for cocaine doses up to $0.063 \mathrm{mg} / \mathrm{infusion}$, responding for cocaine was reduced (treatment, $\mathrm{F}_{1,8}=11.06, p=0.01$; treatment $\times$ dose, $\mathrm{F}_{4,32}=26.38, p<0.001$; Figure $3 \mathrm{~b}$ and $\mathrm{c}$ ). Thus, after infusion of $\alpha$-flupenthixol into the DLS, the dose-response curve for cocaine shifted rightward and downward.

\section{Dopamine in NAcc Shell and DLS and Cocaine Self-Administration: PR Schedule of Reinforcement}

To test whether $\alpha$-flupenthixol affected the motivation for cocaine, we evaluated the effects of $\alpha$-flupenthixol infusions into the NAcc shell and DLS on responding for cocaine under a PR schedule of reinforcement (Richardson and Roberts, 1996), using an ST chain (ie, ST-PR) schedule of self-administration (Olmstead et al, 2000). In animals responding for cocaine under an ST-PR schedule of reinforcement, $\alpha$-flupenthixol infusions into the NAcc shell decreased breakpoints, which was significant for all doses of $\alpha$-flupenthixol tested $\left(3.75,7.5\right.$ and $15 \mu \mathrm{g} ; \chi_{3}^{2}=15.96$ $p=0.001$; Figure $4 \mathrm{a})$. Infusion of $\alpha$-flupenthixol into the DLS also reduced responding for cocaine under an ST-PR schedule of reinforcement, which was significant for the two highest doses of $\alpha$-flupenthixol (7.5 and $15 \mu \mathrm{g} ; \chi_{3}^{2}=12.30$, $p=0.006$; Figure $4 \mathrm{~b}$ ).

\section{Dopamine in NAcc Shell and DLS and Cocaine Self- Administration: Acquisition of Self-Administration Under an FR-1 Schedule of Reinforcement}

The findings that dopamine in the DLS was involved in cocaine self-administration in animals with limited drug experience raised the question whether this region is involved from the very first stages of cocaine selfadministration onwards. Therefore, we infused $\alpha$-flupenthixol into the NAcc shell or the DLS of cocaine-naive rats during the acquisition of cocaine self-administration under an FR-1 schedule of reinforcement. $\alpha$-Flupenthixol administered into the NAcc shell during the first five selfadministration sessions suppressed the acquisition of cocaine self-administration ( $\alpha$-flupenthixol, $F_{1,11}=11.24$, $P=0.006 ; \quad \alpha$-flupenthixol $\times$ session, $F_{4,44}=3.18, \quad p=0.02$; Figure 5a). As soon as $\alpha$-flupenthixol treatment was 

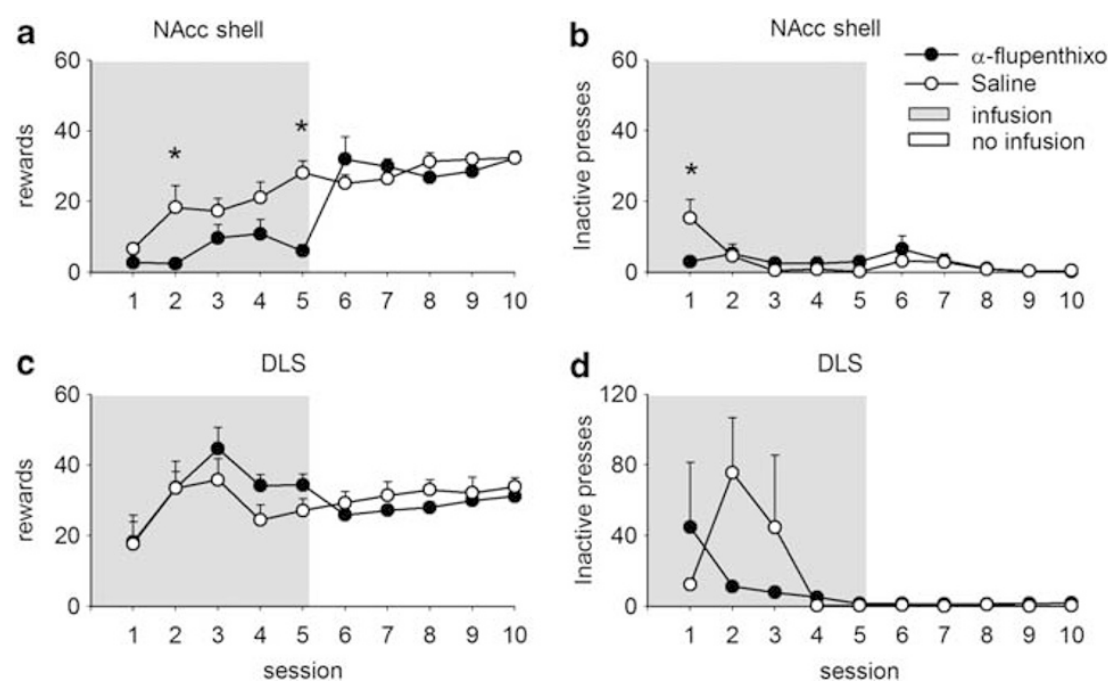

Figure 5 Effects of intracerebral infusions of $\alpha$-flupenthixol on the acquisition of intravenous cocaine self-administration under an FR-I schedule of reinforcement. Graphs express (a, c) the number of rewards (ie, cocaine infusions) obtained or (b, d) the number of inactive lever presses during the 2-h self-administration session following infusion of saline or $\alpha$-flupenthixol into either (a,b) the NAcc shell (saline: $n=6 ; \alpha$-flupenthixol: $n=7$ ) or (c, $d$ ) the DLS (saline: $n=7 ; \alpha$-flupenthixol: $n=10$ ). Data are presented as mean \pm SEM, $* p<0.05$, different from saline (paired t-test).

discontinued, rats responded at the same level as control rats (session 5 saline $v s \alpha$-flupenthixol $t_{11}=5.81, p<0.0001$; session 6 saline $v s \quad \alpha$-flupenthixol $t_{11}=-0.93 \quad p=0.37$; $\alpha$-flupenthixol group session 5 vs session $6, t_{6}=-3.97$, $p=0.007)$. Moreover, there was no effect of previous $\alpha$ flupenthixol treatment in the subsequent five self-administration sessions (sessions 6-10; $\alpha$-flupenthixol, $F_{1,11}=0.02$, $p=0.89$ ) and there was no further change in self-administration during these sessions in either group (sessions 6-10; $\alpha$-flupenthixol $\times$ session, $\mathrm{F}_{4,44}=1.87, p=0.13$ ). There was a general effect of acquisition on the inactive lever presses (sessions $1-5, \quad F_{4,44}=4.26, \quad p=0.005 ;$ sessions 6-10, $\mathrm{F}_{4,44}=3.09, p=0.03$; Figure $5 \mathrm{~b}$ ) and an interaction between session and treatment for the first five sessions $\left(\mathrm{F}_{4,44}=3.87\right.$, $p=0.009)$. Further analysis showed that this was the result of the saline group responding more on the inactive lever than the animals treated with $\alpha$-flupenthixol in the first sessions. From the second session onwards, both groups showed comparable low levels of responding on the inactive lever. Infusion of $\alpha$-flupenthixol into the DLS during the first five self-administration sessions had no effect on the acquisition of cocaine self-administration (sessions $1-5 ; \alpha$ flupenthixol, $\mathrm{F}_{1,15}=1.00, p=0.33 ; \alpha$-flupenthixol $\times$ sessions $1-5, F_{4,60}=0.44, p=0.78$; sessions $6-10 ; \alpha$-flupenthixol, $\mathrm{F}_{1,15}=1.16, p=0.30 ; \alpha$-flupenthixol $\times$ session, $\mathrm{F}_{4,60}=0.79$, $p=0.54$; Figure $5 c$ ). Discontinuation of $\alpha$-flupenthixol treatment reduced cocaine taking on day 6 ( $\alpha$-flupenthixol group session $5 v s$ session $6, t_{9}=3.34, p=0.009$ ), although there were no differences between the $\alpha$-flupenthixol and the saline group during sessions 5 and 6 (session 5, $t_{15}=-1.55, p=0.14$; session $6, t_{15}=1.03, p=0.32$ ). This suggests that $\alpha$-flupenthixol already has a mild effect on cocaine self-administration after five sessions. There was no general effect of acquisition on the inactive lever presses (sessions 1-5; $\alpha$-flupenthixol, $\mathrm{F}_{4,60}=1.67, p=0.17$; $\alpha$-flupenthixol $\times$ session, $\quad \mathrm{F}_{4,60}=1.84, \quad p=0.13 ;$ sessions 6-10; $\alpha$-flupenthixol, $\mathrm{F}_{4,60}=0.12, p=0.98 ; \alpha$-flupenthixol $\times$ session, $\mathrm{F}_{4,60}=0.12, p=0.97$; Figure $5 \mathrm{~d}$ ). During the second five sessions, responding on the inactive lever was somewhat increased in the $\alpha$-flupenthixol group, most likely a result of the very low levels of responding on the inactive lever in the saline group (average number of inactive presses in sessions 6-10: saline $0.2 \pm 0.1$ presses/session; $\alpha$-flupenthixol $1.4 \pm 1.0$ presses/session; $\mathrm{F}_{1,15}=5.89, p=0.03$ ).

\section{DISCUSSION}

The present experiments show that suppression of dopaminergic neurotransmission in the DLS increased cocaine self-administration under an FR-1 schedule of reinforcement, caused a rightward and downward shift of the dose-response curve of cocaine, decreased the reinforcing efficacy of cocaine tested under a PR schedule of reinforcement, but did not affect the acquisition of cocaine self-administration. Suppression of dopaminergic neurotransmission in the NAcc shell inhibited the acquisition of cocaine self-administration, reduced responding for the drug under FR-1 and PR schedules of reinforcement, and caused a downward shift of the dose-response curve of cocaine self-administration. Infusion of $\alpha$-flupenthixol into the DLS did not affect sucrose self-administration under an FR-1 schedule of reinforcement, whereas intra-NAcc shell infusion of $\alpha$-flupenthixol reduced it. Suppression of dopaminergic neurotransmission in the NAcc core or the DMS did not affect responding for cocaine under an FR-1 schedule of reinforcement. These data show that dopamine in both ventromedial (ie, NAcc shell) and dorsolateral regions of the striatum is involved in the reinforcing properties of cocaine.

In this study, we systematically characterized the role of the DLS in the reinforcing properties of cocaine. This adds to our understanding of DLS mechanisms in addictive behavior, since previous studies have for the most part focused on its role in cue-induced drug seeking, rather than drug taking (Ito et al, 2002; Vanderschuren et al, 2005; 
Fuchs et al, 2006; See et al, 2007; Belin and Everitt, 2008; Bossert et al, 2009). Studies investigating the role of the dorsal striatum (although not the DLS studied here) have reported mixed effects of infusion of the dopamine D1 receptor antagonist SCH23390 into a caudal portion of the dorsal striatum on cocaine self-administration under an FR5 schedule of reinforcement (Maldonado et al, 1993; Caine et al, 1995). One study found no effect (Maldonado et al, 1993), while the delayed increase in cocaine self-administration in another study (Caine et al, 1995) was interpreted as being the result of diffusion of the antagonist into adjacent regions, perhaps the more rostral parts of the DLS targeted in the present study. These studies suggest that caudal regions of the dorsal striatum only have a limited role in cocaine self-administration. Given the heterogeneity of the dorsal striatum, with different functions being subserved by its medial $v s$ lateral and rostral $v s$ caudal regions (Voorn et al, 2004; Yin et al, 2004, 2005; Corbit and Janak, 2007; Corbit and Janak, 2010), these results are not necessarily at odds with our findings. Rather, they indicate that different subregions of the dorsal striatum have distinct roles in food and drug reinforcement (Everitt and Robbins, 2005; Yin et al, 2008). Indeed, studies investigating rostral portions of the dorsal striatum have shown that infusion of $\alpha$-flupenthixol into the DLS increased cocaine selfadministration under an FR-1 schedule of reinforcement in rats previously trained and tested under a second-order schedule of reinforcement (Vanderschuren et al, 2005). Recently, electrolytic lesions of central (ie, inbetween medial and lateral) regions of the rostral dorsal striatum were shown to reduce self-administration of cocaine and morphine under a PR schedule of reinforcement (Suto et al, 2011). Our present results suggest that suppressing dopaminergic neurotransmission in the DLS reduces the rewarding properties of cocaine. Animals increased their drug intake under an FR-1 schedule of reinforcement, most likely to compensate for the decreased rewarding effects of cocaine after infusion of the dopamine receptor antagonist (De Wit and Wise, 1977; Ettenberg et al, 1982; Caine and Koob, 1994). The PR and dose-response experiments are consistent with this explanation. The reduction of breakpoints under the PR schedule of reinforcement, which occurs at the same doses of $\alpha$-flupenthixol that increase responding for cocaine under the FR-1 schedule, may be the result of decreased rewarding properties of cocaine. Under a PR schedule of reinforcement, compensation for decreased drug reward by taking more drug infusions is not likely to happen, because the response requirement increases after every drug infusion. Thus, when the rewarding properties of cocaine were reduced after intra-DLS infusion of $\alpha$-flupenthixol, the rats would consequently be less motivated to respond for the drug, resulting in lower breakpoints. Moreover, the rightward shift of the dose-response curve for higher unit doses of cocaine indicates that dopamine receptor blockade in the DLS decreases the rewarding properties of the drug (Altman et al, 1996; Ahmed and Koob, 1998; Piazza et al, 2000). The downward shift in the dose-response curve for the lower unit doses of cocaine is consistent with this notion. By suppressing dopaminergic neurotransmission in the DLS, the rewarding properties of low doses of cocaine could become so low that animals no longer compensate for the lower cocaine reward by taking more drug infusions and therefore ceased responding for the drug.

Suppressing dopaminergic neurotransmission in the DLS did not affect the acquisition of cocaine self-administration. This is in agreement with previous findings that cocaine-naive rats do not self-administer cocaine into dorsal regions of the striatum (Ikemoto, 2003) and that the dorsal striatum is not required for the acquisition of instrumental learning (Hernandez et al, 2002; Atallah et al, 2007). However, cocaine self-administration significantly decreased as soon as $\alpha$-flupenthixol treatment was discontinued, that is, after only five self-administration sessions. This suggests that DLS dopamine already becomes involved in cocaine taking after very limited experience with the drug. The involvement of the DLS in cocaine reinforcement became more pronounced as soon as self-administration had stabilized. This involvement of DLS dopamine in instrumental responding was specific for cocaine, since intra-DLS $\alpha$-flupenthixol did not alter responding for sucrose.

Before concluding that dopamine in the DLS is involved in the rewarding properties of cocaine, alternative explanations must be considered, however. The DLS has a prominent role in stimulus-response habit learning (Packard and Knowlton, 2002; Yin and Knowlton, 2006), and Tiffany (1990) proposed that both seeking and taking drugs can become automatic and habitual. Therefore, one could argue that the changes in cocaine self-administration after infusion of $\alpha$-flupenthixol into the DLS were the result of a suppression of habitual aspects of cocaine use, rather than cocaine reward. However, we do not think that our results can be explained by dopamine in the DLS mediating habitual aspects of drug taking. If dopamine receptor blockade in the DLS suppresses habitual behavior (Faure et al, 2005), intra-DLS infusion of $\alpha$-flupenthixol should have decreased, rather than increased, cocaine self-administration under the FR-1 schedule of reinforcement. Thus, although we did not strictly test whether cocaine selfadministration was habitual using devaluation or extinction procedures (Dickinson, 1985; Dickinson et al, 2002; Miles et al, 2003; Zapata et al, 2010), our results are not consistent with a habit-like pattern of responding for cocaine. In fact, the limited operant experience of our animals under FR-1 or PR schedules of reinforcement is not likely to be sufficient to engage a habitual form of self-administration (Zapata et al, 2010), in contrast to variable interval schedules that more readily promote the development of habitual behavior (Dickinson, 1985). Alternatively, habitual forms of behavior or stereotyped behavior induced by cocaine mediated by the DLS may compete for behavioral output with ventral striatal mechanisms (Joyce and Iversen, 1984). In this scheme, habits or stereotyped behavior mediated by the DLS may serve as a functional brake on behaviors mediated by the ventral striatum, such as goal-directed cocaine self-administration. Releasing this brake on ventral striatal mechanisms by suppressing dopaminergic neurotransmission in the DLS would then result in an increase in cocaine taking. However, our dose-response data do not support the notion that suppression of dopaminergic neurotransmission in the DLS facilitates goal-directed cocaine taking, since responding did not increase for all cocaine unit doses tested. In fact, responding for the lowest cocaine unit doses actually 
decreased. Furthermore, if suppression of DLS dopaminergic neurotransmission facilitates goal-directed forms of cocaine self-administration, then breakpoints under the PR schedule of reinforcement should have increased after intra-DLS $\alpha$-flupenthixol infusion, whereas we observed decreased breakpoints. Taken together, our data indicate that DLS dopamine mediates the rewarding properties of cocaine in animals with limited drug experience, expanding the role of the DLS in drug use beyond habitual aspects of cue-controlled drug seeking after extended drug taking experience.

Blockade of dopamine receptors in the ventral NAcc shell attenuated responding for cocaine both during the acquisition and maintenance of cocaine self-administration. The dose-response analysis showed a suppression of cocaine taking for all unit doses of cocaine, resulting in a pronounced downward shift of the dose-response curve. Infusion of $\alpha$-flupenthixol into the NAcc shell markedly reduced responding for cocaine under a PR schedule of reinforcement. This pattern of effects indicates that dopamine receptor blockade in the NAcc shell decreases the motivation to respond for cocaine, the rewarding properties of the drug, or both. In the acquisition experiment, responding was profoundly decreased during intra-NAcc shell treatment with $\alpha$-flupenthixol, but immediately increased to control levels when dopaminergic neurotransmission in the NAcc shell was no longer suppressed. This suggests that during the first five selfadministration sessions, the animals did learn some rewarding effects of cocaine, but since these were much reduced, they only consumed small quantities of the drug. In addition, the motivation of the animals to respond for the drug could also be inhibited by $\alpha$-flupenthixol. As soon as dopaminergic neurotransmission was no longer blocked, the rewarding and motivational properties of cocaine were experienced in full, leading to levels of responding comparable to those of saline-treated rats. In animals trained to respond for cocaine under an FR-1 schedule of reinforcement, intra-NAcc shell $\alpha$-flupenthixol reduced selfadministration. FR-1 schedules of reinforcement assess reward consumption, which is the result of a variety of processes, including the rewarding and motivational properties of rewards. Therefore, reductions in responding for cocaine could indicate a lower rewarding effect of cocaine, or a lower motivation to respond. After systemic or intra-NAcc treatment with dopamine receptor antagonists, animals usually compensate for the decreased rewarding effects of cocaine by consuming more of the drug (De Wit and Wise, 1977; Ettenberg et al, 1982; Maldonado et al, 1993; McGregor and Roberts, 1993; Caine and Koob, 1994; Caine et al, 1995; Bachtell et al, 2005; Suto et al, 2009). When the rewarding effects of cocaine are reduced further, animals will show decreased levels of self-administration, resembling an extinction-like pattern of responding (De Wit and Wise, 1977; Ettenberg et al, 1982; Caine and Koob, 1994). Thus, the effect of intra-NAcc shell $\alpha$-flupenthixol on responding for cocaine under an FR-1 schedule of reinforcement indicates that either the rewarding effects of cocaine were much reduced, or the motivation to respond for the drug was inhibited. We investigated these possibilities further using a dose-response analysis of cocaine self-administration. Reduced cocaine reward by intra-NAcc shell treatment with $\alpha$-flupenthixol would then be expected to result in a rightward shift of the dose-response curve, whereas a downward shift indicates that the motivation for the drug was affected (Altman et al, 1996; Ahmed and Koob, 1998; Piazza et al, 2000). We found that intra-NAcc treatment with $\alpha$-flupenthixol induced a marked downward shift of the dose-response curve of cocaine, suggesting that the motivation to respond for cocaine was decreased. Motivational influences on behavior can be more directly addressed using a PR schedule of reinforcement (Hodos, 1961; Richardson and Roberts, 1996). Therefore, we also investigated the effect of intra-NAcc shell $\alpha$-flupenthixol on responding for cocaine under a PR schedule of reinforcement, and we found a marked decrease in breakpoints. Interestingly, responding under the PR schedule was more sensitive to $\alpha$-flupenthixol than responding under an FR-1 schedule, since a four-fold lower dose of $\alpha$-flupenthixol reduced responding for cocaine under the PR schedule than under the FR-1 schedule of reinforcement. Together, these data suggest that infusion of $\alpha$-flupenthixol into the ventral NAcc shell reduced the motivation to respond for cocaine, although an effect on the rewarding effects of the drug cannot be ruled out.

Interestingly, in previous studies, infusions of dopamine receptor antagonists into more medial portions of the NAcc shell resulted in increased cocaine self-administration under an FR-1 schedule of reinforcement, indicating reduced cocaine reward, rather than reduced motivation (Caine et al, 1995; Bachtell et al, 2005). In the present study, we aimed our microinfusions at the most ventral portion of the NAcc shell to cover the entire ventromedial to dorsolateral extent of the striatum in our experiments (Voorn et al, 2004). These infusion sites in the NAcc shell bordered on the olfactory tubercle (see Figure 1), which has been implicated in the initiation of cocaine self-administration (Ikemoto, 2003). Therefore, it is likely that the effects of $\alpha$-flupenthixol infusions into the ventral NAcc shell were in part mediated within the olfactory tubercle. Together, this suggests that the rewarding and motivational properties of cocaine are mediated by dopamine in distinct subregions of the ventral striatum, consistent with the reported functional heterogeneity of this structure along its mediolateral as well as rostrocaudal axis (Reynolds and Berridge, 2002; Ikemoto et al, 2005; Smith and Berridge, 2007; Lammel et al, 2011).

Administration of $\alpha$-flupenthixol into the NAcc shell also attenuated sucrose self-administration under an FR-1 schedule of reinforcement. Dopamine in the NAcc shell has been implicated in the vigor of responding for food, rather than in its positive subjective, rewarding properties (Cardinal et al, 2002; Baldo and Kelley, 2007; Salamone et al, 2007). The motivation for food, tested under a PR schedule of reinforcement, has been shown to depend on dopamine neurotransmission in the NAcc (Aberman et al, 1998; Zhang et al, 2003, but see Bari and Pierce, 2005). Remarkably, however, the effects of dopaminergic manipulations on responding for food are usually observed under demanding schedules of reinforcement, whereas intra-shell administration of $\alpha$-flupenthixol in our study reduced responding for sucrose under an FR-1 schedule of reinforcement. This indicates that dopamine in the ventral region of the NAcc shell targeted in the present study may mediate the 
motivation for both drugs and natural rewards, again reflecting the functional heterogeneity of the most ventral regions of the striatum (Reynolds and Berridge, 2002; Ikemoto et al, 2005; Smith and Berridge, 2007; Lammel et al, 2011).

A limitation of the present study was the use of a nonselective dopamine receptor antagonist. This drug was chosen in order to investigate the role of dopaminergic innervation of different subregions of the striatum in the reinforcing properties of cocaine, rather than studying the different dopamine receptor subtypes involved. Previous studies have shown that within the NAcc, both dopamine D1 and D2 (but not D3 or D4) receptors mediate the reinforcing properties of cocaine (Bachtell et al, 2005; Bari and Pierce, 2005; Suto et al, 2009). The type of dopamine receptor that mediates the rewarding properties of cocaine within the DLS remains to be tested in future studies.

The absence of an effect of dopamine receptor blockade in the NAcc core and the DMS on responding under an FR-1 schedule suggests that these regions are not critical for cocaine taking. However, given that different subregions of the striatum have complementary roles in instrumental responding (Everitt and Robbins, 2005; Yin et al, 2008), it is likely that these structures do mediate other aspects of the reinforcing and addictive properties of cocaine (Bari and Pierce, 2005; McFarland and Kalivas, 2001; Di Ciano and Everitt, 2001; Suto et al, 2009).

It is likely that the NAcc shell and DLS mediate cocaine reinforcement in concert, and that ventral striatal mechanisms allow for the involvement of the DLS in cocaine selfadministration to develop. This may occur through a spiraling pathway from ventral to dorsal striatum via the striatal projections to the ventral tegmental area (VTA) and substantia nigra pars compacta (SNc) (Nauta et al, 1978; Haber et al, 2000). Alternatively, shorter pathways may be responsible for the connection between the NAcc shell and DLS, such as the projection from the NAcc shell to the medial SNc that in turn innervates the DLS (van Dongen et al, 2009), or projections within the VTA-nigral complex from VTA to the medial SNc (Ferreira et al, 2008). These possibilities remain to be tested in future studies.

In sum, our study sheds new light on the role of different striatal regions in the early stages of cocaine use. We show that dopamine in both the DLS and NAcc shell is involved in cocaine reinforcement. The DLS and the NAcc shell likely mediate somewhat distinct facets of the reinforcing properties of cocaine, related to its rewarding and motivational aspects, respectively.

\section{ACKNOWLEDGEMENTS}

This work was supported by ZonMw (the Netherlands Organization for Health Research and Development) Grant 91207006 (awarded to LJMJV, P Voorn and AB Smit), ZonMw (the Netherlands Organization for Health Research and Development)/National Institute on Drug Abuse (NIDA) Collaborative Grant 60-60600-97-211 (awarded to LJMJV and RC Pierce) and Brain Foundation of the Netherlands (Hersenstichting), Grant 13F05(2).26. We thank Viviana Trezza and Jules Limpens for assistance, and Chris Pierce and Pieter Voorn for constructive comments on the manuscript.

\section{DISCLOSURE}

The authors declare that, except for income received from their primary employers, no financial support or compensation has been received from any individual or corporate entity over the past three years for research or professional service and there are no personal financial holdings that could be perceived as constituting a potential conflict of interest.

\section{REFERENCES}

Aberman JE, Ward SJ, Salamone JD (1998). Effects of dopamine antagonists and accumbens dopamine depletions on timeconstrained progressive-ratio performance. Pharmacol Biochem Behav 61: 341-348.

Ahmed SH, Koob GF (1998). Transition from moderate to excessive drug intake: change in hedonic set point. Science 282: 298-300.

Atallah HE, Lopez-Paniagua D, Rudy JW, O’Reilly RC (2007). Separate neural substrates for skill learning and performance in the ventral and dorsal striatum. Nat Neurosci 10: 126-131.

Altman J, Everitt BJ, Glautier S, Markou A, Nutt D, Oretti R et al. (1996). The biological, social and clinical bases of drug addiction: commentary and debate. Psychopharmacology 125: 285-345.

Bachtell RK, Whisler K, Karanian D, Self DW (2005). Effects of intra-nucleus accumbens shell administration of dopamine agonists and antagonists on cocaine-taking and cocaine-seeking behaviors in the rat. Psychopharmacology 183: 41-53.

Baldo BA, Kelley AE (2007). Discrete neurochemical coding of distinguishable motivational processes: insights from nucleus accumbens control of feeding. Psychopharmacology 191: 439-459.

Bari AA, Pierce RC (2005). D1-like and D2 dopamine receptor antagonists administered into the shell subregion of the rat nucleus accumbens decrease cocaine, but not food, reinforcement. Neuroscience 135: 959-968.

Bechara A (2005). Decision making, impulse control and loss of willpower to resist drugs: a neurocognitive perspective. Nat Neurosci 8: 1458-1463.

Belin D, Everitt BJ (2008). Cocaine seeking habits depend upon dopamine-dependent serial connectivity linking the ventral with the dorsal striatum. Neuron 57: 432-441.

Bossert JM, Wihbey KA, Pickens CL, Nair SG, Shaham Y (2009). Role of dopamine $\mathrm{D}(1)$-family receptors in dorsolateral striatum in context-induced reinstatement of heroin seeking in rats. Psychopharmacology 206: 51-60.

Caine SB, Heinrichs SC, Coffin VL, Koob GF (1995). Effects of the dopamine D-1 antagonist SCH 23390 microinjected into the accumbens, amygdala or striatum on cocaine self-administration in the rat. Brain Res 692: 47-56.

Caine SB, Koob GF (1994). Effects of dopamine D-1 and D-2 antagonists on cocaine self-administration under different schedules of reinforcement in the rat. J Pharmacol Exp Ther 270: 209-218.

Cardinal RN, Parkinson JA, Hall J, Everitt BJ (2002). Emotion and motivation: the role of the amygdala, ventral striatum, and prefrontal cortex. Neurosci Biobehav Rev 26: 321-352.

Corbit LH, Janak PH (2007). Inactivation of the lateral but not medial dorsal striatum eliminates the excitatory impact of Pavlovian stimuli on instrumental responding. J Neurosci 27: 13977-13981.

Corbit LH, Janak PH (2010). Posterior dorsomedial striatum is critical for both selective instrumental and Pavlovian reward learning. Eur J Neurosci 31: 1312-1321. 
De Wit H, Wise RA (1977). Blockade of cocaine reinforcement in rats with the dopamine receptor blocker pimozide, but not with the noradrenergic blockers phentolamine or phenoxybenzamine. Can J Psychol 31: 195-203.

Di Ciano P, Everitt BJ (2001). Dissociable effects of antagonism of NMDA and AMPA/KA receptors in the nucleus accumbens core and shell on cocaine-seeking behavior. Neuropsychopharmacology 25: 341-360.

Dickinson A (1985). Actions and habits - the development of behavioral autonomy. Philos Trans R Soc Lond B Biol Sci 308: 67-78.

Dickinson A, Wood N, Smith JW (2002). Alcohol seeking by rats: action or habit? Q J Exp Psychol B 55: 331-348.

Ettenberg A, Pettit HO, Bloom FE, Koob GF (1982). Heroin and cocaine intravenous self-administration in rats: mediation by separate neural systems. Psychopharmacology 78: 204-209.

Everitt BJ, Robbins TW (2005). Neural systems of reinforcement for drug addiction: from actions to habits to compulsion. Nat Neurosci 8: 1481-1489.

Faure A, Haberland U, Conde F, El Massioui N (2005). Lesion to the nigrostriatal dopamine system disrupts stimulus-response habit formation. J Neurosci 25: 2771-2780.

Ferreira JG, Del Fava F, Hasue RH, Shammah-Lagnado SJ (2008). Organization of ventral tegmental area projections to the ventral tegmental area-nigral complex in the rat. Neuroscience 153: 196-213.

Fuchs RA, Branham RK, See RE (2006). Different neural substrates mediate cocaine seeking after abstinence versus extinction training: a critical role for the dorsolateral caudate-putamen. J Neurosci 26: 3584-3588.

Gerrits MAFM, van Ree JM (1996). Effect of nucleus accumbens dopamine depletion on motivational aspects involved in initiation of cocaine and heroin self-administration in rats. Brain Res 713: 114-124.

Haber SN, Fudge JL, McFarland NR (2000). Striatonigrostriatal pathways in primates form an ascending spiral from the shell to the dorsolateral striatum. J Neurosci 20: 2369-2382.

Hernandez PJ, Sadeghian K, Kelley AE (2002). Early consolidation of instrumental learning requires protein synthesis in the nucleus accumbens. Nat Neurosci 5: 1327-1331.

Hodos W (1961). Progressive ratio as a measure of reward strength. Science 134: 943-944.

Ikemoto S (2003). Involvement of the olfactory tubercle in cocaine reward: intracranial self-administration studies. J Neurosci 23: 9305-9311.

Ikemoto S, Qin M, Liu ZH (2005). The functional divide for primary reinforcement of $\mathrm{D}$-amphetamine lies between the medial and lateral ventral striatum: is the division of the accumbens core, shell, and olfactory tubercle valid? J Neurosci 25: 5061-5065.

Ito R, Dalley JW, Howes SR, Robbins TW, Everitt BJ (2000). Dissociation in conditioned dopamine release in the nucleus accumbens core and shell in response to cocaine cues and during cocaine-seeking behavior in rats. J Neurosci 20: 7489-7495.

Ito R, Dalley JW, Robbins TW, Everitt BJ (2002). Dopamine release in the dorsal striatum during cocaine-seeking behavior under the control of a drug-associated cue. J Neurosci 22: 6247-6253.

Joyce EM, Iversen SD (1984). Dissociable effects of 6-OHDAinduced lesions of neostriatum on anorexia, locomotor activity and stereotypy: the role of behavioural competition. Psychopharmacology 83: 363-366.

Kasanetz F, Deroche-Gamonet V, Berson N, Balado E, Lafourcade M, Manzoni O et al. (2010). Transition to addiction is associated with a persistent impairment in synaptic plasticity. Science 328: 1709-1712.
Koob GF, Ahmed SH, Boutrel B, Chen SA, Kenny PJ, Markou A et al. (2004). Neurobiological mechanisms in the transition from drug use to drug dependence. Neurosci Biobehav Rev 27: 739-749.

Lammel S, Ion DI, Roeper J, Malenka RC (2011). Projectionspecific modulation of dopamine neuron synapses by aversive and rewarding stimuli. Neuron 70: 855-862.

Letchworth SR, Nader MA, Smith HR, Friedman DP, Porrino LJ (2001). Progression of changes in dopamine transporter binding site density as a result of cocaine self-administration in rhesus monkeys. J Neurosci 21: 2799-2807.

Maldonado R, Robledo P, Chover AJ, Caine SB, Koob GF (1993). D1 dopamine receptors in the nucleus accumbens modulate cocaine self-administration in the rat. Pharmacol Biochem Behav 45: 239-242.

McFarland K, Kalivas PW (2001). The circuitry mediating cocaineinduced reinstatement of drug-seeking behavior. J Neurosci 21: 8655-8663.

McGregor A, Roberts DCS (1993). Dopaminergic antagonism within the nucleus accumbens or the amygdala produces differential effects on intravenous cocaine self-administration under fixed and progressive ratio schedules of reinforcement. Brain Res 624: 245-252.

Miles FJ, Everitt BJ, Dickinson A (2003). Oral cocaine seeking by rats: action or habit? Behav Neurosci 117: 927-938.

Moore RJ, Vinsant SL, Nader MA, Porrino LJ, Friedman DP (1998). Effect of cocaine self-administration on dopamine D2 receptors in rhesus monkeys. Synapse 30: 88-96.

Nader MA, Daunais JB, Moore T, Nader SH, Moore RJ, Smith HR et al. (2002). Effects of cocaine self-administration on striatal dopamine systems in rhesus monkeys: initial and chronic exposure. Neuropsychopharmacology 27: 35-46.

Nauta WJ, Smith GP, Faull RL, Domesick VB (1978). Efferent connections and nigral afferents of the nucleus accumbens septi in the rat. Neuroscience 3: 385-401.

Olmstead MC, Parkinson JA, Miles FJ, Everitt BJ, Dickinson A (2000). Cocaine-seeking by rats: regulation, reinforcement and activation. Psychopharmacology 152: 123-131.

Packard MG, Knowlton BJ (2002). Learning and memory functions of the basal ganglia. Annu Rev Neurosci 25: 563-593.

Paxinos G, Watson C (1998). The Rat Brain in Stereotaxic Coordinates. Academic Press: San Diego.

Perry JL, Carroll ME (2008). The role of impulsive behavior in drug abuse. Psychopharmacology 200: 1-26.

Pettit HO, Ettenberg A, Bloom FE, Koob GF (1984). Destruction of dopamine in the nucleus accumbens selectively attenuates cocaine but not heroin self-administration in rats. Psychopharmacology 84: 167-173.

Piazza PV, Deroche-Gamonent V, Rouge-Pont F, Le Moal M (2000). Vertical shifts in self-administration dose-response functions predict a drug-vulnerable phenotype predisposed to addiction. J Neurosci 20: 4226-4232.

Pierce RC, Kumaresan V (2006). The mesolimbic dopamine system: the final common pathway for the reinforcing effect of drugs of abuse? Neurosci Biobehav Rev 30: 215-238.

Pierce RC, Vanderschuren LJMJ (2010). Kicking the habit: the neural basis of ingrained behaviors in cocaine addiction. Neurosci Biobehav Rev 35: 212-219.

Porrino LJ, Lyons D, Smith HR, Daunais JB, Nader MA (2004). Cocaine self-administration produces a progressive involvement of limbic, association, and sensorimotor striatal domains. J Neurosci 24: 3554-3562.

Reynolds SM, Berridge KC (2002). Positive and negative motivation in nucleus accumbens shell: bivalent rostrocaudal gradients for GABA-elicited eating, taste 'liking'/'disliking' reactions, place preference/avoidance, and fear. J Neurosci 22: 7308-7320. 
Richardson NR, Roberts DCS (1996). Progressive ratio schedules in drug self-administration studies in rats: a method to evaluate reinforcing efficacy. J Neurosci Methods 66: 1-11.

Roberts DCS, Corcoran ME, Fibiger HC (1977). On the role of ascending catecholaminergic systems in intravenous self-administration of cocaine. Pharmacol Biochem Behav 6: 615-620.

Roberts DCS, Koob GF, Klonoff P, Fibiger HC (1980). Extinction and recovery of cocaine self-administration following 6-hydroxydopamine lesions of the nucleus accumbens. Pharmacol Biochem Behav 12: 781-787.

Robinson TE, Berridge KC (2003). Addiction. Annu Rev Psychol 54: 25-53.

Rodd-Henricks ZA, McKinzie DL, Li TK, Murphy JM, McBride WJ (2002). Cocaine is self-administered into the shell but not the core of the nucleus accumbens of Wistar rats. J Pharmacol Exp Ther 303: 1216-1226.

Salamone JD, Correa M, Farrar A, Mingote SM (2007). Effortrelated functions of nucleus accumbens dopamine and associated forebrain circuits. Psychopharmacology 191: 461-482.

See RE, Elliott JC, Feltenstein MW (2007). The role of dorsal vs ventral striatal pathways in cocaine-seeking behavior after prolonged abstinence in rats. Psychopharmacology 194: 321-331.

Smith KS, Berridge KC (2007). Opioid limbic circuit for reward: interaction between hedonic hotspots of nucleus accumbens and ventral pallidum. J Neurosci 27: 1594-1605.

Suto N, Ecke LE, Wise RA (2009). Control of within-binge cocaineseeking by dopamine and glutamate in the core of nucleus accumbens. Psychopharmacology 205: 431-439.

Suto N, Wise RA, Vezina P (2011). Dorsal as well as ventral striatal lesions affect levels of intravenous cocaine and morphine selfadministration in rats. Neurosci Lett 493: 29-32.

Tiffany ST (1990). A cognitive model of drug urges and drug-use behavior: role of automatic and nonautomatic processes. Psychol Rev 97: 147-168.

van Dongen YC, Kolomiets BP, Groenewegen HJ, Thierry AM, Deniau JM (2009). A subpopulation of mesencephalic dopamine neurons interfaces the shell of nucleus accumbens and the dorsolateral striatum in rats. In: Groenewegen HJ, Berendse HW, Cools AR, Voorn P, Mulder AB (eds). The Basal Ganglia IX. Springer: New York. pp 119-130.
Vanderschuren LJMJ, Di Ciano P, Everitt BJ (2005). Involvement of the dorsal striatum in cue-controlled cocaine seeking. J Neurosci 25: 8665-8670.

Vanderschuren LJMJ, Everitt BJ (2005). Behavioral and neural mechanisms of compulsive drug seeking. Eur J Pharmacol 526: 77-88.

Volkow ND, Li TK (2004). Drug addiction: the neurobiology of behaviour gone awry. Nat Rev Neurosci 5: 963-970.

Volkow ND, Wang GJ, Telang F, Fowler JS, Logan J, Childress AR et al. (2006). Cocaine cues and dopamine in dorsal striatum: mechanism of craving in cocaine addiction. J Neurosci 26: 6583-6588.

Voorn P, Vanderschuren LJMJ, Groenewegen HJ, Robbins TW, Pennartz CMA (2004). Putting a spin on the dorsal-ventral divide of the striatum. Trends Neurosci 27: 468-474.

Wise RA (2004). Dopamine, learning and motivation. Nat Rev Neurosci 5: 483-494.

Wong DF, Kuwabara H, Schretlen DJ, Bonson KR, Zhou Y, Nandi A et al. (2006). Increased occupancy of dopamine receptors in human striatum during cue-elicited cocaine craving. Neuropsychopharmacology 31: 2716-2727.

Yin HH, Knowlton BJ, Balleine BW (2004). Lesions of dorsolateral striatum preserve outcome expectancy but disrupt habit formation in instrumental learning. Eur J Neurosci 19: 181-189.

Yin HH, Ostlund SB, Knowlton BJ, Balleine BW (2005). The role of the dorsomedial striatum in instrumental conditioning. Eur $\mathrm{J}$ Neurosci 22: 513-523.

Yin HH, Knowlton BJ (2006). The role of the basal ganglia in habit formation. Nat Rev Neurosci 7: 464-476.

Yin HH, Ostlund SB, Balleine BW (2008). Reward-guided learning beyond dopamine in the nucleus accumbens: the integrative functions of cortico-basal ganglia networks. Eur J Neurosci 28: 1437-1448.

Zapata A, Minney VL, Shippenberg TS (2010). Shift from goaldirected to habitual cocaine seeking after prolonged experience in rats. J Neurosci 30: 15457-15463.

Zhang M, Balmadrid C, Kelley AE (2003). Nucleus accumbens opioid, GABaergic, and dopaminergic modulation of palatable food motivation: contrasting effects revealed by a progressive ratio study in the rat. Behav Neurosci 117: 202-211. 